\title{
AVALIAÇÃO DE PROFESSORES: QUE LIÇÕES DO CASO PORTUGUÊS?
}

\begin{tabular}{|c|c|}
\hline & Resumo \\
\hline $\begin{array}{c}\text { Eusébio José Machado } \\
\text { Universidade Portucalense - Porto - } \\
\text { Portugal } \\
\text { Marta Abelha } \\
\text { Universidade Portucalense - Porto - } \\
\text { Portugal }\end{array}$ & $\begin{array}{l}\text { No atual contexto de "omniavaliação", a } \\
\text { avaliação de professores assume um } \\
\text { papel central nas políticas educativas e } \\
\text { na construção da profissionalidade } \\
\text { docente, surgindo dilacerada } \\
\text { entrepressões de performatividade e } \\
\text { desejos emancipatórios. Neste aspecto, } \\
\text { as mudanças ocorridas em Portugal, } \\
\text { sobretudo no período entre } 2007-2013 \\
\text { facultam contributos muito pregnantes } \\
\text { para a discussão das lógicas, processos } \\
\text { e dispositivos de avaliação de } \\
\text { professores, quer no que respeita às } \\
\text { implicações endógenas, quer no que } \\
\text { respeita aos efeitos exógenos. No } \\
\text { âmbito deste artigo, a partir do acervo } \\
\text { de investigação realizada em Portugal, } \\
\text { discutimos os resultados obtidos e } \\
\text { retiramos as principais lições sobre a } \\
\text { análise de dois aspetos que têm } \\
\text { merecido particular destaque na } \\
\text { literatura: i) a avaliação centrada na } \\
\text { escola e ii) a avaliação pelos pares. }\end{array}$ \\
\hline & $\begin{array}{l}\text { Palavras-chave: Avaliação } \\
\text { professores; Avaliação pelos pares; } \\
\text { Profissionalidade docente. }\end{array}$ \\
\hline
\end{tabular}




\title{
TEACHER EVALUATION: WHAT CAN WE LEARN FROM THE PORTUGUESE CASE?
}

\begin{abstract}
In the current context of "omnievaluation", teacher evaluation plays a central role in educationpolicy and in the construction of teacher professionality, appearing divided between pressures of performativity and emancipatory desires. In this aspect, changes occurredin Portugal, especially in the period between 2007-2013, provide very pregnant contributions to the discussion of logics, processes and mechanisms of teacher evaluation, regarding eitherto endogenous implications or to exogenous effects. Considering the research conducted in Portugal, this article discusses the results and proposesthe mainlessons on the analysis of two aspects that have received particular attention in the literature: i) the school centered evaluation and ii) the peer evaluation.
\end{abstract}

Keywords: Teacher evaluation; Peer evaluation; Teacher professionality. 


\begin{abstract}
"Para se emancipar alguém, é preciso ser-se emancipado. É preciso conhecer-se a si mesmo como viajante do espírito, parecido com todos os outros viajantes, como sujeito intelectual participante da potência comum dos seres intelectuais."
\end{abstract}

J. RANCIÈRE (2010, p. 40)

1. A avaliação de professores num contexto de "omniavaliação": profissionalidade e performatividade ${ }^{1}$

Ao longo das últimas décadas, assistimos a uma profunda e paradigmática mudança na educação, em consonância, aliás, com mudanças noutros setores sociais, cujo traço principal é a emergência de uma lógica performativa generalizada (LYOTARD, 1974), a qual tem funcionado quer como discurso de legitimação, quer como regulador da ação, consubstanciando-se na prevalência de uma "metanarrativa do controlo" (ALVES \& MACHADO, 2011). Segundo Day (2004), esta transformação em curso é marcada pela substituição das fortes tradições liberais e humanistas, assentes numa visão não instrumental e no valor intrínseco da educação, por políticas educativas funcionalistas e performativas que procuram responder ao aumento da competividade econômica através de reformas centradas na accountability (AFONSO, 2011), no salário associado ao mérito e nas formas de regulação indiretas e recentralizadas. Neste contexto, Machado (2013) aponta para a instauração de um "regime de omniavaliação", do qual resultam, pelo menos, três consequências evidentes no âmbito educacional:

\footnotetext{
${ }^{1}$ Estudo realizado no âmbito do Projeto de investigação financiado pela Fundação para a Ciência e Tecnologia (Referência PTDC/CPE-CED/104786/2008, Projeto ADDin - "Avaliação do Desempenho Docente: compreender a sua complexidade para a tomada de decisões fundamentadas na investigação", sediado no Departamento de Educação da Universidade de Aveiro.

Olh@res, Guarulhos, v. 2, n. 1, p. 55-80. Maio, 2014.
} 
- antes de mais, a passagem de "políticas de avaliação" para uma "avaliação como política" (LIMA, 2011), reconhecendo que, ao contrário de certa vulgata sociológica, não há um afastamento, mas uma reconfiguração do papel do Estado na regulação da educação que passa por estratégias mais subtis, insidiosas e eficazes, nas quais avulta, invariavelmente, a centralidade da avaliação;

- por outro lado, a passagem de uma lógica de separação e de especialização para uma lógica de democratização e universalização das funções de avaliadores e de avaliados (todos são, ao mesmo tempo, avaliadores e avaliados), o que permite convocar democraticamente todos os intervenientes para uma regulação (re)centralizada do Estado;

- finalmente, o reforço das práticas de autoavaliação, último avatar da omniavaliação, conciliando, ao mesmo tempo, a legitimidade individualista das atuais sociedades democráticas com interiorização, no próprio sujeito, da esquizofrenia avaliativa: mais do que cada um ser avaliador dos outros e avaliado dos outros, o que importa é cada um seja, finalmente, avaliador e avaliado de si próprio.

Neste movimento das placas tectônicas em que assenta a educação movimento impercetível, mas inexorável - é evidente que a profissionalidade docente tem vindo a sofrer, pelo menos nos últimos trinta anos, grandes transformações que, segundo Tardif e Foucher, se realizam sob o signo da "obrigação de resultados" e da "responsabilização", traduzindo-se em "avaliações que visam, essencialmente, que os professores determinem a eficácia das suas práticas pedagógicas - de apoio à aprendizagem - e das suas práticas de avaliação" (2010, p. 33). Deste ponto de vista, as bases nas quais se construiu a profissionalidade docente (NÓVOA, 1991), sobretudo, ao longo da modernidade, começam a tornar-se incomensuráveis com este paradigma emergente, designadamente a legitimação a partir de uma narrativa emancipatória. As várias "figuras" da profissão docente (ESTRELA, 2011), desde o "Mestre" (STEINER, 2005) até à do 
"prático reflexivo" (SCHÖN, 1987), radicadas numa retórica humanista do professor como agente do progresso dos sujeitos, da cidade e da humanidade, perderam - ou estão em vias de perder - a sua pregnância profissional, científica e social face à figura do "professor performativo" que se torna hegemónica (ALVES, FLORES \& MACHADO, 2011).

A avaliação de professores, como processo formal, intencionalizado e integrado nas "novas" políticas de gestão pública (BARROSO, 2005), não pode ser dissociada deste conjunto de transformações que tem vindo ocorrer de modo consistente nas últimas décadas e por todo o mundo (LADERRIÈRE,2008; FLORES, 2010; PAQUAY, 2004). Não obstante, a literatura tem acentuado a importância da avaliação de desempenho para a melhoria e "qualidade" do trabalho docente, sendo considerado um elemento fundamental para o desenvolvimento profissional, a promoção da reflexividade crítica e a autorregulação profissional. Por isso, entre as pressões da performatividade e os desejos emancipatórios, a avaliação de professores é, hoje em dia, um campo de fortíssimas tensões (PAQUAY, 2004, pp. 306-308): tensões relativas ao referencial de avaliação (o que é que se avalia?), tensões relativas às funções (regular ou controlar?), tensões relativas aos atores (quem avalia?) e tensões relativas ao modo de pilotagem do sistema educativo (centralização ou autonomia?). É neste contexto que se justifica, a partir do conhecimento das práticas, a procura das condições ou dos fatores que possam constituir uma avaliação “mobilizadora" (PAQUAY, 2004), de “qualidade" (STRONGE, 2010) e "válida" (GATTI, 2011), uma vez que "todos nós, seja qual for a nossa relação com o empreendimento educativo, merecemos uma avaliação de elevada qualidade", com a qual seja possível "promover a aprendizagem ao longo da vida e a eficácia pedagógica dos professores" (STRONGE, 2010, p. 40). 


\section{A avaliação de professores em Portugal: um enquadramento histórico-concetual}

Segundo Machado, Abelha, Barreira e Salgueiro (2012), a evolução diacrônica da avaliação de professores em Portugal é marcada pela existência de três períodos distintos, a saber: $1^{\circ}$ período: até 1974 , no qual predomina a "heteroavaliação externa"; $2^{\text {o }}$ período: entre 1974 e 2007, durante o qual se assiste a uma hegemonia da autoavaliação, sendo eliminado qualquer lógica de exterioridade; e o $3^{\circ}$ período: desde 2007 até à atualidade que se traduz numa "lógica de heteroavaliação interna, baseando-se na avaliação pelos pares, combinando-a com a autoavaliação e lógicas de exterioridade mitigada" (MARCOS, 2013, p. 331).

Com efeito, até 1974 (Revolução do 25 de abril), sob a prevalência de um regime ditatorial, a avaliação de professores obedecia a um sistema que pode ser caracterizado como de "heteroavaliação externa", no qual se postula o princípio de que "os avaliadores pertencem a organizações ou sistemas exteriores, independentes e neutros, garantindo um efeito de objetividade e distanciamento para uma avaliação que se pretende isenta de subjetividade e parcialidade, como também isenta de conflitos intra-organizacionais" (MACHADOet al., 2012, p. 74). Assim, durante este período, numa lógica de controle científico, pedagógico e, sobretudo, político (mas sem preocupação primordial com os "resultados"), a avaliação de professores era realizada pela Inspeção Geral de Educação e pelos reitores das escolas: os avaliadores eram inspetores nomeados pela IGE que comparavam as observações que realizavam às aulas dos docentes com os pareceres emitidos pelos reitores. Neste sistema de "heteroavaliação externa", coerente com a natureza ditatorial do regime, verificava-se uma relação de verticalidade hierárquica, sem qualquer dimensão formativa ou dialógica, no âmbito da qual os professores - enquanto "objetos" da avaliação - estavam 
impossibilitados de qualquer tipo de participação no processo de avaliação e, por maioria de razão, na discussão dos próprios resultados.

Em abril de 1974, Portugal viveu um período de revolução em que se assistiu à passagem de um regime ditatorial para um regime democrático e, até 1986, “a questão da ADD [avaliação do desempenho docente] esteve afastada da agenda política dos sucessivos governos, uma vez que a mesma se encontrava conotada a aspetos como punição e controle que caracterizavam o passado autocrático" (MACHADO et al., 2012, p. 77). No entanto, em 1986, a questão da avaliação de professores regressou à agenda política, com a publicação da Lei de Bases do Sistema Educativo (Lei n. ${ }^{\circ}$ 46/86 de 14 de outubro), assumindo-a numa ótica de progressão na carreira e de prestação de contas. A regulamentação do processo de avaliação de professores surge, então, com o Decreto n. ${ }^{\circ}$ 14/92 de 4 de julho que tinha como principais objetivos revigorar a autonomia das escolas e potenciar o desenvolvimento profissional dos professores, apontando, deste modo, para uma retórica eminentemente emancipatória, participativa e autorreguladora.

Assim, o processo de avaliação de professores consistia na apresentação, por parte do docente avaliado, dos seguintes elementos: i) de um documento de reflexão crítica sobre as atividades desenvolvidas no período de tempo de serviço a que se reportava a avaliação do desempenho e ii) da certificação das ações de formação contínua concluídas, para efeitos da respetiva creditação. Após análise desses elementos de avaliação, era atribuída, pelo presidente do órgão de gestão, uma menção qualitativa ao docente avaliado. Estávamos, deste modo, perante um sistema de avaliação com caráter predominantemente internalista (MACHADO, 2009) e centrado na autoavaliação, dado que "os principais atores de todo esse processo eram os próprios docentes avaliados e como figura de avaliador o presidente do órgão de gestão. Somente em casos excecionais se 
constituíam equipas mistas de avaliadores, com elementos internos e externos à escola" (MACHADOet al., 2012, p. 79).

Em 1998, perante o caráter, essencialmente, "administrativo" - não indutor de reflexão sobre as práticas curriculares do professor avaliado - que moldava o processo de avaliação de professores, o Ministério da Educação decidiu introduzir alterações ao processo de avaliação do desempenho docente, nomeadamente ao rever o Estatuto da Carreira Docente (Decreto-Lei n. ${ }^{\circ} 1 / 98$ de 2 de janeiro), que passou a ter como ambição "associar uma nova valorização da profissão docente a uma acrescida responsabilidade dos docentes, garantir condições de acesso à formação contínua e instituir mecanismos de avaliação e de diferenciação interna, tomando como referência a qualidade do respectivo desempenho profissional". Contudo, o processo de avaliação de professores continuava, à semelhança do regime anterior, a exigir um "documento de reflexão crítica" sobre a atividade desenvolvida pelo docente avaliado acompanhado da certificação das ações de formação concluídas, que eram posteriormente alvo de análise quer pelo órgão de gestão, quer por uma comissão de três ou cinco elementos designados pelo conselho pedagógico. De acordo com as investigações de Curado (2002) e de Simões (1998), o "documento de reflexão crítica" nada mais era do que um pró-forma burocrático, com uma natureza mais descritiva do que propriamente reflexiva, traduzindo-se num procedimento meramente administrativolegal que servia, essencialmente, para ascender na carreira docente.

Assiste-se, portanto, no período pós-revolucionário, a uma alteração no processo de avaliação de professores, passando a dominar um sistema radical de autoavaliação, em que o "documento de reflexão crítica" elaborado pelo avaliado adotava, simultaneamente com o certificado das ações de formação concluídas e creditadas, primordial importância no processo de avaliação. Porém, embora se admita a utilidade do "documento de reflexão crítica", dado que coadjuva os professores na análise das suas práticas curriculares docentes, "não deixa também de ser reduzido a uma classificação administrativa sem 
qualquer efeito de diferenciação" (PACHECO \& FLORES, 1999, p. 189). Na perspetiva dos mesmos autores, apesar de os pressupostos contingentemente inovadores, o processo de avaliação de professores, que é objeto de regulamentação em 1998, conserva o propósito da certificação e ignora o objetivo do desenvolvimento profissional docente e das escolas. Continuou-se, assim, "perante um processo de avaliação burocrático e rotineiro, que não responsabilizava os professores pela sua ação docente, sendo o principal objetivo a prestação de contas para progredir na carreira" (MACHADOet al., 2012, p. 79).

Em 2007, convocando estes pressupostos, o Ministério da Educação decidiu encetar uma espécie de revolução coperniciana, configurando um sistema de avaliação de professores paradigmaticamente diferente do anterior.A principal ambição retórica era um "sistema de avaliação mais exigente", que fomentasse e valorizasse o "mérito profissional do docente" com repercussões no desenvolvimento da sua carreira. Pretendia-se, assim, que a avaliação de professores deixasse de se fundamentar única e exclusivamente na autoavaliação (“documento de reflexão crítica" elaborado pelo docente). Neste sentido, foram introduzidas várias alterações, as quais, não obstante uma certa tergiversação legislativa ${ }^{2}$ resultante, em larga medida, de um clima de grande contestação e polêmica, marcam o atual sistema de avaliação de professores em Portugal:

a) o caráter radicalmente internalista da avaliação, conferindo à escola total autonomia na definição do quadro de referência, na construção dos instrumentos e na organização do processo de avaliação;

b) o postulado da universalidade da avaliação: todos são avaliados, todos os anos e em todos os domínios do quadro de referência;

\footnotetext{
${ }^{2}$ Desde 2008 até ao presente, houve uma elevada produção legislativa, correspondendo a vários ciclos de avaliação, da qual se destacam os seguintes normativos: Decreto Regulamentar 2/2008, de 10 de janeiro, Decreto-Regulamentar 1A/2009, de 5 de janeiro, Decreto Regulamentar n. ${ }^{\circ}$ 2/2010, de 23 de junho e Regulamentar n. ${ }^{\circ}$ 26/2012, de 21 de fevereiro.
} 
c) o princípio da autorregulação através de uma avaliação pelos pares na base de uma hierarquia mitigada e softapesar da recente introdução da figura do avaliador externo (um par de uma outra escola);

d) a existência de observação de aulas como principal (e praticamente único) instrumento de recolha de informação sobre o desempenho científico e pedagógico, assumindo uma natureza compulsiva em determinados momentos da carreira;

e) o afunilamento artificial da carreira através da introdução de um regime de contingentação (o recurso a "quotas") no acesso às menções de mérito e aos vários escalões que constituem a carreira;

f) a coexistência de lógicas formativas e, até, supervisivas com lógicas sumativas e meramente classificativas;

g) e, sobretudo, a prevalência de um modelo de heteroavaliação (interna e externa), apesar de conviver com processos de autoavaliação que não foram eliminados.

Esta configuração do sistema de avaliação de professores português é marcada por um conjunto de tensões, algumas das quais de natureza constitutiva e que atravessam as soluções encontradas em diversos países, como já referimos. Do ponto de vista da legitimação, trata-se de um conjunto de opções que reforça o controle do desempenho e aumenta o processo de responsabilização através dos resultados, colocando-se em linha com mudanças atuais na profissionalidade docente. É evidente, por outro lado, a introdução de princípios de seletividade e de meritocracia cuja principal consequência é a produção de carreiras desiguais e caracterizadas por uma progressiva relação entre o salário e o mérito. No entanto, é preciso reconhecer que, não obstante, o presente sistema de avaliação de professores apresenta, pelo menos, duas características de elevado potencial emancipatório, formativo e promotor do desenvolvimento profissional: a avaliação centrada na escola e a avaliação pelos pares. Trata-se, aliás, de aspetos que são congruentes com as opções mais 
estruturantes relativamente à profissionalidade docente e com a maior parte da literatura publicada.

Ora, são justamente estas duas características que pretendemos confrontar com a investigação que tem sido feita em Portugal desde 2008, procurando, assim, inferir as principais "lições" que o caso português poderá legitimar.

3. A investigação sobre avaliação de professores em Portugal: uma revisão crítica (2008-2013)

As mudanças introduzidas na avaliação de professores em Portugal a partir de 2007 tiveram um impacto que ultrapassou largamente a comunidade educativa e as escolas e tornou-se, efetivamente, um assunto que, devido à significativa projeção mediática e política, envolveu toda a população portuguesa e provocou um dos maiores movimentos de protesto no campo da educação. No domínio da investigação e da literatura científica, verificou-se, também, um interesse acrescido e generalizado, multiplicando-se o número de trabalhos de mestrado e de doutoramento na maior parte das universidades portuguesas (públicas e privadas).

Com efeito, no trabalho de recenseamento da investigação realizada em Portugal sobre avaliação de professores, que incidiu nos repositórios das universidades portuguesas, (públicas e privadas), Mesquita-Alves, Costa e Machado (2011) identificaram, entre 2007 e 2011, catorze investigações, (mestrados) distribuídas pelas Universidades de Coimbra (4), de Lisboa (4), de Braga (3), do Porto (2) e de Aveiro (1), cujas principais problemáticas foram (1) relação entre a avaliação de professores e o desenvolvimento profissional, (2) processos de supervisão em contexto de avaliação de professores, (3) práticas de regulação em contexto de avaliação de professores e (4) autonomia versus heteronomia na construção/operacionalização da 
avaliação de professores (MESQUITA-ALVES et al., 2011, p. 670). Por sua vez, Marcos (2013), entre 2011-2013, recenseou 23 trabalhos científicos (19 teses de mestrados e 3 teses de doutoramento) que se distribuem pelas Universidades do Minho (4), de Lisboa (2), de Aveiro (1), Coimbra (1), da Beira (1), Católica (4), Portucalense (2), pelas Escolas Superiores de Educação de Leiria (1) e de Lisboa (2) e pelo Instituto Superior de Educação e Trabalho do Porto (1). Durante este período, as principais problemáticas abordadas foram (i) supervisão e o desenvolvimento profissional, (ii) conceções, tensões, desafios, práticas e perspetivas da avaliação de professores e (iii) operacionalização do processo de avaliação.

No âmbito deste artigo, convocaremos seletivamente os contributos deste acervo de investigação para analisar os dois aspetos acima referidos, os quais, aliás, merecem particular destaque não só pela sua relativa originalidade e, até, radicalidade, mas, sobretudo, pelo facto de corresponderem a opções que são potenciadoras, à partida, de uma avaliação de professores de qualidade, dotada de sentido e válida para o desenvolvimento profissional.

\subsection{A avaliação centrada na escola}

Segundo Danielson (2001), uma das novas tendências da avaliação de professores é a centralidade da escola na organização dos processos avaliativos, o que permite assumir, como acontece no caso português, uma elevada autonomia na definição do quadro de referência, na construção dos instrumentos de apoio e na seleção e orientação dos próprios avaliadores. Assumindo um carácter contextualizado e "em situação", a avaliação pode atender aos contextos específicos do desempenho profissional, bem como desenvolver processos de avaliação mais reguladores formativos e supervisivos (VIEIRA \&ALFREDO, 2012). Na definição de um sistema de "avaliação de qualidade", Stronge (2010) enfatiza, também, a relação da avaliação de professores com os objetivos da organização e a importância do 
contexto, destacando várias aspetos de natureza contextual como, por exemplo, as disciplinas que o docente leciona, a dimensão da turma, as condições e qualidade da sala de aula, os recursos para o exercício da profissão docente e os recursos para o desenvolvimento profissional docente.

No atual sistema de avaliação de professores em Portugal, há uma orientação claramente internalista e contextualizada, o que nos permite afirmar que estamos perante um sistema de avaliação de professores centrado na escola. Desde logo, a definição do referencial de avaliação (os chamados "parâmetros") é da responsabilidade da escola a partir dos seus documentos de referência, em particular do projeto educativo, sendo que, se o professor pretender aumentar o grau de particularização do seu referencial de desempenho, tem ainda possibilidade de elaborar um "projeto docente". Por outro lado, é a escola que organiza internamente o processo de avaliação, designadamente no que respeita à calendarização do processo e aos "instrumentos de registo" para recolha de informação. Acresce, ainda, que os avaliadores são todos internos, ou seja, pares do mesmo grupo disciplinar e com posição igual ou superior na carreira, embora, recentemente, tenha sido introduzida a figura do "avaliador externo" (a única diferença em relação ao avaliador interno é a obrigatoriedade de pertencer a uma escola diferente do avaliado).

Referindo-se ao período entre 2007-2009 (extensível, mutatis mutandis, ao período atual), Salgueiro e Costa (2013) identificam três lógicas de ação organizacional na avaliação de professores: uma "lógica burocrática" resultante de um processo de operacionalização excessivamente complexo devido, sobretudo, à necessidade de um sobre-envolvimento das escolas e dos professores na construção, aplicação e preenchimento de documentos (objetivos individuais, planos de aula, ficha de autoavaliação, grelha de observação de aulas, etc.); uma "lógica conflitual" decorrente, principalmente, da avaliação pelos pares e da competividade inerente ao processo de avaliação, 
através da qual se criaram fatores de hierarquização no seio de uma cultura profissional muito paritária; e, finalmente, uma "lógica artificial" marcada pela consciência dos diferentes atores de que a avaliação de professores não visa o desenvolvimento profissional e organizacional, mas uma forma de controlar, vigiar e "fiscalizar" o trabalho dos professores. Salgueiro e Costa concluem, afirmando que, "para além da burocratização do processo que ocupou tempo excessivo aos docentes, os dois fatores de maior controvérsia e que maiores dificuldades criaram foram a divisão da carreira e a atribuição da função avaliativa aos professores titulares, no âmbito de uma das maiores inovações deste sistema - a avaliação pelos pares" (2013, p. 104).

A lógica de conflitualidade é, também, um dos aspetos assinalados por Alves e Aguiar (2013). Para estes autores, a avaliação de professores provocou e até agudizou um regime de tensões, sobretudo na sua dimensão intraescolar. A centralidade quase absoluta da escola na organização do processo de avaliação deu origem a uma acumulação de trabalho de natureza burocrática, a um acréscimo de responsabilidades e, principalmente, a "um clima de desconfiança, bem como a existência de vários conflitos, tendo-se criado, por consequência, uma grande desmotivação e distanciação entre os docentes, o que, muitas vezes, se traduz em situações, não só de isolamento, mas também de competividade entre os professores" (ALVES\& AGUIAR, 2013, p. 146). Neste aspeto, outros estudos realizados (FILIPE, 2011; OLIVEIRA, 2012; RIBEIRO, 2011) mostram que um dos efeitos perversos da avaliação centrada na escola é a diminuição ou, até, anulação das práticas colaborativas devido, por um lado, a uma falta de tempo resultante do excesso de "burocracia", e, por outro, ao aumento da competividade entre pares. Além disso, segundo Marcos (2013), a conflitualidade intraorganizacional e interpares contribuiu para uma redução das lógicas supervisivas entre avaliadores e avaliados, comprometendo uma das maiores potencialidades da opção por uma "avaliação em situação". 
A investigação realizada em Portugal confirma, por outro lado, que um dos pontos críticos de um sistema de avaliação centrado na escola é o próprio processo de referencialização (FIGARI, 1996). Com efeito, o postulado da centralidade da escola na avaliação de professores pressupõe uma capacidade endógena para construir referenciais de desempenho, instrumentos de registo e processos de operacionalização, de natureza mais ou menos participativa e dialógica, através dos quais se cumpram os objetivos de desenvolvimento profissional, da reflexão e da supervisão. Ora, segundo Silva e Machado (2013), a construção dos instrumentos de registo - uma das exigências cruciais numa avaliação de natureza eminentemente interna - revelou-se como uma das maiores dificuldades "técnicas" que terá desencadeado um processo "burocrático", complexo e "desumanizado", do qual resultou uma perceção da avaliação marcada pela "subjetividade", ambiguidade e falta de equidade. A imputação da responsabilidade do processo exclusivamente à escola resultou, assim, na emergência de obstáculos organizacionais e técnicos que enviesaram, claramente, as potencialidades formativas e emancipatórias de uma avaliação centrada na escola e baseada num processo de referencialização autônomo e dialógico.

\subsection{Avaliação pelos pares}

A avaliação pelos pares foi, seguramente, a grande mudança que o sistema de avaliação de professores estabeleceu a partir de 2008, assentando numa lógica de "heteroavaliação interna" combinada com uma componente autoavaliação sob a forma de um "relatório de reflexão crítica". Neste sentido, e tal como afirma Marcos, uma vez que os avaliadores são pares, assumindo um estatuto paritário, participam e conhecem o contexto onde decorre a avaliação, dever-seia estar perante uma opção que "deveria ser o garante da implementação de mecanismos consensuais que permitissem o 
desenvolvimento de lógicas mais reguladoras, participativas e supervisivas com o intuito da melhoria da ação docente" (2013, p. 462). Contudo, resultados de diversas investigações (AGUIAR, 2011; ARAÚJO, 2013; CARDOSO, 2012; FIGUEIREDO, 2009; MARCOS, 2013; MESQUITA, 2013; MOTA, 2009; RAMALHO, 2012; TEIXEIRA, 2010) demonstram um cenário completamente diferente, imperando nas escolas lógicas de ação docente de natureza marcadamente individualista, acompanhadas de um clima de competição e conflito entre pares, o que, paradoxalmente, parece ser imputado ao facto dos avaliadores serem pares.

A competitividade/isolamento é, segundo Alves e Aguiar, um efeito negativo resultante da avaliação de desempenho ser realizada pelos pares, não contribuindo assim para o "desenvolvimento do professor, quer como profissional, quer como pessoa (...) [o] conduz ao enfraquecimento da relação entre os docentes e, por consequência, à degradação do ambiente escolar" (2013, p. 146). Por outro lado, a falta de formação específica e de competências para esta "nova" função de avaliar os pares é outro dos constrangimentos apontados a este sistema de avaliação de professores quer por professores avaliados, quer por professores avaliadores (ARAÚJO, 2013). De resto, a questão "quem devem ser os avaliadores" não reúne consenso entre os professores participantes nas diversas investigações (CARDOSO, 2012; CARNEIRO, 2011; GOMES, 2010), oscilando as opiniões dos professores de que os avaliadores deveriam ser: I)professores exteriores à escola; II) uma equipa mista constituída por professores exteriores e professores da escola; III) docentes do ensino superior com formação na área da avaliação.

A literatura (HADJI, 1994; MACHADO et al., 2012; NOVAES, 2011) demonstra que a avaliação de professores só faz sentido se assumir uma função formativa cuja finalidade é o desenvolvimento profissional docente. No entanto, resultados do estudo desenvolvido por Marcos (2013) assinalam que, para os professores avaliados, o atual sistema de avaliação de professores em Portugal assume um 
caráter marcadamente classificativo e não formativo, pois não consideram que durante o processo exista, por parte dos avaliadores, feedback construtivo e relevante para o desenvolvimento profissional dos docentes avaliados. A este propósito, resultados de investigações realizadas em Portugal demonstram, ainda, que os professores avaliados assinalam a intervenção dos avaliadores como sendo de caráter pontual e com um cunho burocrático-legal, alertando, juntamente com os avaliadores, para a necessidade de maior investimento na formação dos avaliadores (ARAÚJO, 2013; MESQUITA, 2013; RODRIGUES, 2011). Saliente-se que “este não reconhecimento de competências para avaliar é fator de insatisfação, contestação e mau ambiente dentro das escolas" (ARAÚJO, 2013, p. 75).

Estudos realizados por Figueiredo (2009) e Alves e Aguiar (2013) sustentam que, de acordo com a opinião dos professores, a realização da avaliação docente com recurso aos pares é influenciada pela questão da proximidade entre avaliador e avaliado, isto é, as relações de amizade entre avaliador e avaliado podem comprometer a isenção do processo de avaliação por parte dos avaliadores. Em contrapartida, uma má relação entre pares (avaliador e avaliado) poderá enviesar o processo de avaliação. Neste sentido, o papel de avaliador é visto como uma situação "geradora de tensão, revelando-se como sendo uma situação obrigatória, ingrata e delicada, não só pelo fato de os próprios professores avaliadores não estarem de acordo com o modelo aplicado, mas também pelo facto de se impor um cargo cujas responsabilidades inerentes são difíceis de assumir" (ALVES \& AGUIAR, 2013, p. 146).

De acordo com as investigações revisitadas, a avaliação pelos pares é, assim, encarada como um processo penoso, difícil e indutor de um clima de mal-estar entre os docentes. Os resultados das diversas investigações evocadas apontam para, paradoxalmente, a preferência dos professores por "modos avaliativos exteriores ao contexto, quando 
repetidamente se afirma a importância do conhecimento do mesmo para uma avaliação mais rigorosa" (ROLDÃO, 2013, p. 172). Segundo Garcia (2011), avaliação pelos pares assumiu objetivos de classificação e seleção, sendo encarada pelos professores como perturbadora das relações pessoais e fonte de conflitos (CARDOSO, 2012) que enfraqueceram o desenvolvimento de dinâmicas colaborativas. As insuficiências que enformaram o processo de seleção dos avaliadores e a inexistência de formação especializada (COELHO, 2011) terão abalado, também, a legitimidade para o exercício da função e a utilidade do próprio processo de avaliação de professores.

\section{Considerações finais: que lições da avaliação de professores em Portugal?}

Face aos resultados da investigação acima expostos, é possível constatar que o caso português faculta contributos muito pregnantes para a discussão das lógicas, processos e dispositivos de avaliação de professores, quer no que respeita às implicações endógenas, quer no que respeita aos efeitos exógenos. Durante um período relativamente curto de tempo (2007-2013), foram ensaiadas várias soluções, realizaram-se diversas experiências, mudaram-se quadros de referência, intervieram múltiplos atores e escrutinaram-se vantagens e desvantagens dos vários "modelos" adotados, apesar da permanência de aspetos matriciais e constitutivos que não sofreram qualquer alteração como é caso das opções por uma avaliação centrada na escola e feita pelos pares. Trata-se, como já vimos, de aspetos que colocam o sistema de avaliação de professores em vigor em Portugal em consonância com propostas mais recentes que procuram sustentar uma avaliação associada ao desenvolvimento profissional, ao reconhecimento e à reflexividade(DANIELSON, 2001; DE KETELE, 2011; PAQUAY, 2004; STRONGE, 2010). Ora, apesar de a literatura apontar para potencialidades e vantagens na avaliação centrada na 
escola e feita pelos pares, o caso português permitiu sinalizar, com grande detalhe e acuidade, um conjunto de problemas, questões e limitações que importa ter em conta.

No que toca à avaliação centrada na escola, a investigação aponta, de um modo geral, para o seguinte conjunto de conclusões:

a) induz uma agudização de conflitos internos porque provoca a introdução de mecanismos formais e informais de hierarquização (avaliar é poder) entre os professores ou entre os professores e os órgãos de gestão da escola;

b) assume um elevado grau de autonomia das escolas que é dado como adquirido, sendo certo, porém, que existe uma enorme diversidade no que respeita à capacidade organizacional para responder aos desafios da avaliação;

c) aumenta a "burocracia" interna da escola, implicando uma sobreocupação de tempo na tomada de decisão, na produção de instrumentos e na implementação do sistema;

d) reforça a perceção da subjetividade e de relatividade da avaliação, permitindo a construção de referenciais de elevado particularismo e o desenvolvimento de processos de avaliação pouco equitativos.

Admitindo que avaliação de professores centrada na escola ou em situação corresponde a uma opção com elevado potencial formativo e profissional, importa, pois, atentar aos efeitos organizacionais que a avaliação acarreta no ecossistema escolar. Por isso, e de acordo com o caso português, é fundamental capacitar organizacionalmente a escola para integrar nas suas dinâmicas de organização e gestão a avaliação de professores, tendo em conta que, numa lógica de autonomia, deverão ser tomadas posições de natureza técnica e política. O pressuposto de uma avaliação centrada na escola é a autonomia, mas autonomia não é um mero ato volitivo: exige competências, conhecimentos e meios para se concretizar. Deste ponto de vista, uma avaliação centrada na escola exige uma capacitação de competências de gestão e de participação para que os processos não se transformem 
em obstáculos para o desenvolvimento profissional e para a melhoria do próprio processo de ensino e aprendizagem. Neste aspeto, ressaltamos a necessidade de estratégias de natureza formativa que capacitem os diversos intervenientes de competências fundamentais para a construção, gestão e aplicação do dispositivo de avaliação de professores. Além disso, atendendo que é dada a possibilidade à escola de avaliar em situação e em contexto, de tal modo que, dentro de determinados limites, não haverá processos iguais, é indispensável que as exigências normativas - se falarmos de uma avaliação de carácter nacional - sejam claras, simples e exequíveis.

Quanto à avaliação pelos pares, a investigação que acima convocamos legitima as seguintes inferências:

a) aumenta os índices de competividade intraescolar, o que se traduz, por consequência, numa diminuição, em muitos casos, das práticas de colaboração e de trabalho em equipa;

b) inibe, paradoxalmente, as lógicas de supervisão devido ao facto de introduzir processos de hierarquização entre os professores, possuindo, simultaneamente, funções formativas e sumativas;

c) dificulta a objetividade da avaliação que implica uma distanciação que encontra dificuldades de implementação nas culturas profissionais dos professores muito marcadas pela paridade e pela densidade afetiva;

d) exige uma elevada legitimidade/autoridade técnica, científica e profissional dos avaliadores, sob pena de ausência de reconhecimento da validade dos juízos de valor e da importância da avaliação para a profissionalidade docente.

De acordo com estes aspetos, a avaliação pelos pares pressupõe, desde logo, uma elevada competência dos avaliadores para o exercício das suas funções, não bastando para o efeito a legitimidade decorrente da experiência e da senioridade. Não desprezando a importância de uma seleção cuidada de acordo com perfis multidimensionais (competências de relacionamento interpessoal, competências comunicacionais, competências emocionais, competências técnicas, 
etc.), é preciso que os avaliadores sejam capacitados, igualmente, através da formação e da experiência para o desempenho de tarefas que sejam reconhecidas e eficazes. Ao mesmo tempo, a avaliação pelos pares necessita de um clima organizacional com uma elevada propensão colaborativa e supervisiva, sem a qual a avaliação surgirá, irremediavelmente, como um trabalho artificial destinado exclusivamente a gerir as carreiras e a concretizar as lógicas meritocráticas. Sendo certo que as escolas, como todas as organizações, são, também, espaços de conflitos e de interesses antagónicos, a competividade não deve ter como único efeito o isolamento e a autarcia profissional. Neste aspeto, é indispensável que a escola se organize - com espaços e tempos - para facilitar o trabalho colaborativo, a reflexão conjunta e a participação crítica: sem tal clima organizacional será difícil que uma avaliação pelos pares possa cumprir, genuína e cabalmente, os seus propósitos de emancipação profissional. 


\section{Referências}

AFONSO, A. J. Questões polémicas no debate sobre políticas educativas contemporâneas; o caso da accountability baseada em testes estandardizados e rankings escolares. In: ALVES, M.P.; DE KETELE, J.-M. (Org.). Do currículo à avaliação, da avaliação ao currículo. Porto: Porto Editora, 2011. p. 83-101.

AGUIAR, J. O sistema de avaliação de desempenho docente: Tensões e desafios nas escolas e nos professores. Tese (Doutoramento em Educação) - Universidade do Minho. Braga, 1986.

ALVES, M. P.; FLORES, M. A.; MACHADO, E. A. Quanto vale o que fazemos? Práticas de avaliação de desempenho. Santo Tirso: De Facto, 2011.

ALVES, M. P.; MACHADO, E. A. O sentido do currículo e o sentido da avaliação. In: ALVES, M.P.; DE KETELE, J.-M. (Org.). Do currículo à avaliação, da avaliação ao currículo. Porto: Porto Editora, 2011. p. 59-70.

ALVES, M.P., \& AGUIAR, J. O sistema de avaliação de desempenho docente: tensões e desafios nas escolas e nos professores. In: MACHADO, E. A., COSTA, N. \& ALVES, M.P. (Orgs.). Avaliação do desempenho docente: compreender a complexidade, sustentar a decisão. Santo Tirso: De Facto Editores, 2013, p. 125-166.

ARAÚJO, P. Avaliação de desempenho docente na perspetiva dos professores avaliadores. In: MACHADO, E. A., COSTA, N. \& ALVES, M.P. (Orgs.). Avaliação do desempenho docente: compreender a complexidade, sustentar a decisão. Santo Tirso: De Facto Editores, 2013, p. 65-81.

BARROSO, J. Políticas educativas e gestão escolar. Lisboa: Universidade Aberta, 2005.

CARDOSO, A. Avaliação do desempenho docente e o professor titular: um estudo de caso numa perspetiva organizacional. Tese de Doutoramento - Universidade de Aveiro. Aveiro, 2012.

CARNEIRO, M. Avaliação de desempenho e clima de escola. Dissertação de Mestrado - Instituto Superior de Educação e Trabalho. Porto, 2011.

COELHO, A. C. A.Avaliação do desempenho docente: a realidade no $\mathbf{1 .}^{\mathbf{0}}$ Ciclo.Dissertação de Mestrado - Universidade de Coimbra. Coimbra, 2011.

CURADO, A. P. Política de avaliação de professores em Portugal: Um estudo de implementação. Fundação Calouste Gulbenkian. Lisboa, 2002.

DANIELSON, C. New trends in teacher evaluation.Educational leadership, 58 (5), p. 12-15, 2001. 
DAY, C. Evaluer la formation des enseignants dans le contexte d'une école en changement en vue de favoriser le développement professionnel des acteurs et d'améliorer leur efficacité? In: PAQUAY, L. (Org.). L'évaluation des enseignants. Paris : L'Harmattan. p. 97-119, 2004.

DE KETELE, J.-M. A avaliação do desenvolvimento profissional dos professores: postura de controlo ou postura de reconhecimento? In: ALVES, M. P.; MACHADO, E. A. (Org.). O pólo de excelência. Caminhos para avaliação do desempenho docente. Porto: Edições Asa, 2010. p. 13-31.

ESTRELA, M. T. Profissão docente. Dimensões afectivas e éticas. Porto: Edições Asa, 2011.

FIGARI, G.Avaliar: que referencial? Porto: Porto Editora, 1996.

FIGUEIREDO, L. A avaliação de desempenho docente: estudo do processo de implementação com professores de educação especial. Dissertação de Mestrado Universidade do Minho. Braga, 2009.

FILIPE, J. M.O relator enquanto supervisor na avaliação de desempenho docente: uma relação entre a teoria e a prática. Dissertação de Mestrado - Escola Superior de Educação. Leiria, 2011.

FLORES, M. A. Avaliação de professores numa perspetiva internacional. Sentidos e implicações. Porto: Porto Editora, 2010.

GARCIA, M. M. R. Avaliação do desempenho docente: as lógicas profissionais na voz crítica dos professores. Dissertação de Mestrado - Lisboa. Universidade de Lisboa. Lisboa, 2011.

GATTI, B. A. Avaliação de professores: um campo complexo. Estudos em Avaliação Educacional, São Paulo, v. 22, n. 48, p. 77-88, jan./abr. 2011.

GOMES, M. Avaliação do desempenho docente - objetivos e controvérsias. Dissertação de Mestrado - Universidade Lusófona de Humanidades e Tecnologias. Lisboa, 2010.

HADJI, C. A avaliação: regras do jogo - das intenções aos instrumentos. Porto: Porto Editora, 1994.

LADERRIÈRE, P. Tendances actuelles de l'évaluation des enseignants. In: M. GUYAZ (Org.); J. WEISS (Ed.). Actes du Séminaire Quelle évaluation des enseignants au service de l'école? Neuchâtel: IRDP. p. 9-18, 2008.

LIMA. L. Avaliação, competividade e hiperburocracia. In: ALVES, M.P.; DE KETELE, J.-M. (Org.). Do currículo à avaliação, da avaliação ao currículo. Porto: Porto Editora, 2011. p. 71-82.

LYOTARD, J.-F. La condition post-moderne. Paris : Les Éditions de Minuit, 1974. 
MACHADO, E. A. Avaliar é ser sujeito ou sujeitar-se? Mangualde: Edições Pedago, 2013.

MACHADO, E. A. Para uma perspectiva crítica dos "modelos" de avaliação do desempenho docente. Revista do Centro de Formação Francisco de Holanda, ELO, Guimarães, 16, p. 51-60, 2009.

MACHADO, E. A., ABELHA, M., BARREIRA, C., \& SAlGUEIRO, A. Avaliação pelos pares: percurso normativo da avaliação do desempenho docente em Portugal. Revista Portuguesa de Pedagogia, 46 (1), p. 73-93, 2012.

MARCOS, A. Lógicas de supervisão pedagógica em contexto de avaliação de desempenho docente. Tese de doutoramento - Universidade Portucalense. Porto, 2013.

MESQUITA, F. Avaliação do desempenho docente e Supervisão Pedagógica. Tese de Doutoramento - Universidade de Aveiro. Aveiro, 2013.

MESQUITA-ALVES, F.; COSTA, N.; MACHADO, E. A. Investigação em avaliação do desempenho docente: o estado da arte em Portugal. In: Atas do XI Congresso da SPCE, 4, p. 667-672, 2011.

MOTA, V. O novo modelo de avaliação do desempenho docente: Formação e percepções dos agentes avaliativos. Dissertação de Mestrado - Faculdade de Psicologia e de Ciências da Educação da Universidade de Coimbra. Coimbra, 2009.

NOVAES, A. O. Avaliação de desempenho docente: uma experiência formativa para alunos e professores. Estudos em Avaliação Educacional, São Paulo, v. 22, n. 48, p. 11-28, jan./abr. 2011.

NÓVOA, A. Profissão professor. Porto, Porto Editora, 1991.

OLIVEIRA, M. E. S. (2012). O caminho labiríntico da avaliação do desempenho docente: um estudo com professores de línguas estrangeiras. Dissertação de Mestrado -Universidade do Minho. Braga, 2012.

PACHECO, J. A., \& FLORES, M. A. Formação e avaliação dos professores. Porto: Porto Editora, 1999.

PAQUAY, L. L'évaluation des enseignants. Paris: L'Harmattan, 2005.

Olh@res, Guarulhos, v. 2, n. 1, p. 55-80. Maio, 2014. 
RAMALHO, H. Escola, professores e avaliação: Narrativas e racionalidades da avaliação do desempenho docente na escola básica portuguesa. Tese de Doutoramento - Universidade do Minho. Braga, 2012.

RANCIÈRE, J. O mestre ignorante. Cinco lições sobre a emancipação intelectual. Mangualde: Edições Pedago, 2010.

RIBEIRO, F. M.Supervisão entre pares: contributos para a melhoria das práticas de ensino. Dissertação de Mestrado - Universidade Portucalense. Porto, 2011.

ROLDÃO, M.C. Considerações finais - questões emergentes. In: MACHADO, E. A., COSTA, N. \& ALVES, M.P. (Orgs.). Avaliação do desempenho docente: compreender a complexidade, sustentar a decisão. Santo Tirso: De Facto Editores, 2013, p. 167-174.

SALGUEIRO, A.; COSTA, J. A. Lógicas de ação organizacional na avaliação de desempenho docente: dados de um estudo de caso sobre o primeiro ciclo avaliativo. In: MACHADO, E. A., COSTA, N. \& ALVES, M.P. (Orgs.). Avaliação do desempenho docente: compreender a complexidade, sustentar a decisão. Santo Tirso: De Facto Editores, 2013, p. 91-107.

SCHÖN, D. Educating the reflective practitioner.San Francisco: Jossey Bass, 1987.

SILVA, F. L. V.; MACHADO, E. A. Equidade e objetividade na avaliação de desempenho docente: a prática de utilização de instrumentos de registo. In: MACHADO, E. A., COSTA, N. \& ALVES, M.P. (Orgs.). Avaliação do desempenho docente: compreender a complexidade, sustentar a decisão. Santo Tirso: De Facto Editores, 2013, p. 109-124.

SIMÕES, G. A. A avaliação do desempenho docente: contributos para uma análise crítica. Dissertação de mestrado - Faculdade de Psicologia e de Ciências da Educação. Lisboa, 1998.

STEINER, G. As lições dos Mestres. Lisboa: Gradiva, 2005.

STRONGE, J. H. O que funciona, de facto, na avaliação de professores: breves considerações. In: FLORES, M. A. (Org.).Avaliação de professores numa perspetiva internacional. Sentidos e implicações. Porto: Porto Editora, 2010. p. 22-43. 
TARDIF, J.; FOUCHER, C. Um conjunto de balizas para avaliação da profissionalidade docente. In: ALVES, M. P.; MACHADO, E. A. (Org.). O pólo de excelência. Caminhos para avaliação do desempenho docente. Porto: Edições Asa, 2010. p. 3253.

TEIXEIRA, A. A avaliação do desempenho docente e a problemática dos objetivos individuais: Da prescrição às práticas. Dissertação de Mestrado - Instituto de Educação da Universidade do Minho. Braga, 2010.

VIEIRA, F.; ALFREDO, M. A. Supervisão e avaliação do desempenho docente. Para uma abordagem de orientação transformadora. Lisboa: Ministério da Educação/Conselho Científico para a Avaliação de Professores, 2011. 